\title{
Use of Real-Time PCR for Chlamydia psittaci Detection in Human Specimens During an Outbreak of Psittacosis - Georgia and Virginia, 2018
}

\author{
Olivia L. McGovern, $\mathrm{PhD}^{1,2}$; Miwako Kobayashi, MD²; Kelly A. Shaw, $\mathrm{PhD}^{1,3}$; Christine Szablewski, DVM ${ }^{1,4}$; Julie Gabel, DVM ${ }^{4}$; \\ Caroline Holsinger, DrPH ${ }^{3}$; Cherie Drenzek, DVM ${ }^{4}$; Skyler Brennan, $\mathrm{MPH}^{4}$; Jennifer Milucky, $\mathrm{MSPH}^{2}$; Jennifer L. Farrar, $\mathrm{MPH}^{2}$; \\ Bernard J. Wolff, MS²; Alvaro J. Benitez²; Kathleen A. Thurman, $\mathrm{MS}^{2}$; Maureen H. Diaz, PhD²; Jonas M. Winchell, $\mathrm{PhD}^{2}$; Stephanie Schrag, DPhil ${ }^{2}$
}

Psittacosis is typically a mild febrile respiratory illness caused by infection with the bacterium Chlamydia psittaci and usually transmitted to humans by infected birds (1). On average, 11 psittacosis cases per year were reported in the United States during 2000-2017. During August-October 2018, the largest U.S. psittacosis outbreak in 30 years (82 cases identified $^{*}$ ) occurred in two poultry slaughter plants, one each in Virginia and Georgia, that shared source farms (2). CDC used C. psittaci real-time polymerase chain reaction (PCR) to test 54 human specimens from this outbreak. This was the largest number of human specimens from a single outbreak ever tested for $C$. psittaci using real-time PCR, which is faster and more sensitive than commercially available serologic tests. This represented a rare opportunity to assess the utility of multiple specimen types for real-time PCR detection of C. psittaci. C. psittaci was detected more frequently in lower respiratory specimens (59\% [10 of 17]) and stool (four of five) than in upper respiratory specimens (7\% [two of 28]). Among six patients with sputum and nasopharyngeal swabs tested, C. psittaci was detected only in sputum in five patients. Cycle threshold $(\mathrm{Ct})$ values suggested bacterial load was higher in lower respiratory specimens than in nasopharyngeal swabs. These findings support prioritizing lower respiratory specimens for real-time PCR detection of C. psittaci. Stool specimens might also have utility for diagnosis of psittacosis.

\footnotetext{
*Although 80 cases had been reported previously, a retrospective review of $\mathrm{CDC}$ and medical records and discussion with state partners led to an increase of the case count to 82. During September 19-20, 2018, a health hazard evaluation was conducted at the Virginia plant by the National Institute for Occupational Safety and Health at the request of the U.S. Department of Agriculture Food Safety and Inspection Service. Recommendations to reduce worker risk included repositioning cooling fans, ensuring proper function of evisceration tools, and other changes to workplace practices to reduce bacterial contamination and aerosolization.
}

Use of primarily serologic tests for laboratory confirmation of psittacosis might contribute to underdiagnosis. The most commonly available diagnostic tests for psittacosis are commercially available serologic tests. These tests have poor specificity and require testing of paired sera collected weeks apart, delaying or preventing confirmation of clinical diagnoses (3). Real-time PCR assays are sensitive, specific, and can be performed in hours. However, in the United States, real-time

\section{INSIDE}

510 COVID-19 Incidence and Mortality Among American Indian/Alaska Native and White Persons Montana, March 13-November 30, 2020

514 Use of Stay-at-Home Orders and Mask Mandates to Control COVID-19 Transmission - Blackfeet Tribal Reservation, June-December 2020

519 Provisional Mortality Data — United States, 2020

523 Death Certificate-Based ICD-10 Diagnosis Codes for COVID-19 Mortality Surveillance - United States, January-December 2020

528 Community Transmission of SARS-CoV-2 Associated with a Local Bar Opening Event - Illinois, February 2021

533 Notes from the Field: COVID-19 Case Investigation and Contact Tracing Program - Spirit Lake Tribe, North Dakota, September-November 2020

535 COVID-19 Stats

536 QuickStats

Continuing Education examination available at https://www.cdc.gov/mmwr/mmwr_continuingEducation.html

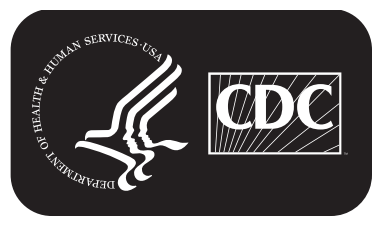

U.S. Department of Health and Human Services Centers for Disease Control and Prevention 
PCR assays for diagnosis of psittacosis using human respiratory specimens are currently available only at CDC (4).

During August 31-September 12, 2018, the Virginia Department of Health and Georgia Department of Public Health were each notified of a cluster of patients hospitalized with symptoms consistent with psittacosis; all worked in one of two chicken slaughter plants that shared source farms, one in Virginia and one in Georgia (2). In Virginia and Georgia, local and state public health officials conducted active case finding to identify illness consistent with psittacosis in persons who worked at one of the plants during August-September 2018. Workers were classified as having probable or confirmed cases of illness based on case definitions. Probable cases were identified based on symptoms and epidemiologic exposures, and confirmed cases were identified based on detection of C. psittaci by real-time PCR in at least one clinical specimen. ${ }^{\dagger}$ Clinical specimens for $C$. psittaci testing were collected from workers seeking medical care, at the discretion of local clinicians, and sent to CDC for real-time PCR testing; no diagnostic testing for psittacosis was performed elsewhere. CDC recommended collection of lower respiratory specimens whenever possible,

\footnotetext{
$\dagger$ Among those who worked at the Virginia plant during August 1-September 7, 2018, or at the Georgia plant during August 13-September 28, 2018, persons with probable cases had physician-diagnosed pneumonia, fever, or chills with two or more of the following: headache, cough, or muscle aches. Patients with confirmed cases had real-time PCR detection of $C$. psittaci in at least one clinical specimen with or without meeting the probable case definition.
}

but all available specimens were accepted and tested. ${ }^{\S}$ Testing was performed in triplicate using extracted total nucleic acid and oligonucleotides targeting the $C$. psittaci locus tag CPSIT_RS01985 on an ABI 7500 real-time PCR system $(4,5)$. A specimen was considered positive for $C$. psittac $i$ if amplification of the CPSIT_RS01985 locus tag was detected. Patient demographic, clinical, and specimen characteristics among the subset of workers who submitted specimens to CDC were determined by patient interview, medical chart abstraction, and laboratory record review.

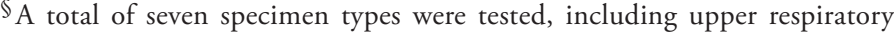
specimens (nasopharyngeal swab or oropharyngeal swab), lower respiratory specimens (sputum or bronchoalveolar lavage), and nonrespiratory specimens (stool, blood, and cerebrospinal fluid).

Total nucleic acid was extracted from all specimens using a MagNA Pure Compact instrument (Roche Diagnostics) with the Roche Total Nucleic Acid Isolation Kit I according to manufacturer instructions; elution volume was $100 \mu \mathrm{L}$. Stool, whole blood, and sputum specimens were preprocessed before nucleic acid extraction. For stool specimens, $200 \mathrm{mg}$ of stool were first resuspended in $2 \mathrm{~mL}$ of phosphate buffered saline (PBS). Then, $400 \mu \mathrm{L}$ of the resuspended stool specimen was inactivated by combining with $400 \mu \mathrm{L}$ MagNA Pure Bacteria Lysis Buffer and $40 \mu \mathrm{L}$ Proteinase K $(25 \mathrm{mg} / \mathrm{mL}$; Thermo Fisher Scientific). Inactivated specimens were subject to mechanical lysis by bead-beat with $0.5 \mathrm{~mm}$ glass beads using a Precellys 24 Homogenizer (Bertin Corp.) at $5,000 \mathrm{rpm}$ for 60 seconds twice with a 5 -second hold in between. The specimen was then centrifuged at $10,000 \times \mathrm{g}$ for 1 minute, and $700 \mu \mathrm{L}$ of supernatant was used for total nucleic acid extraction. Whole blood was not resuspended with PBS, but otherwise underwent the same preprocessing as stool. For sputum specimens, $300 \mu \mathrm{L}$ of the specimen was combined with $300 \mu \mathrm{L}$ of 1,4-Dithiothreitol (12.5mM; Fisher Scientific) and incubated at room temperature for 1 hour.
}

The MMWR series of publications is published by the Center for Surveillance, Epidemiology, and Laboratory Services, Centers for Disease Control and Prevention (CDC), U.S. Department of Health and Human Services, Atlanta, GA 30329-4027.

Suggested citation: [Author names; first three, then et al., if more than six.] [Report title]. MMWR Morb Mortal Wkly Rep 2021;70:[inclusive page numbers].

\section{Centers for Disease Control and Prevention \\ Rochelle P. Walensky, MD, MPH, Director \\ Anne Schuchat, MD, Principal Deputy Director \\ Daniel B. Jernigan, MD, MPH, Acting Deputy Director for Public Health Science and Surveillance \\ Rebecca Bunnell, PhD, MEd, Director, Office of Science \\ Jennifer Layden, MD, PhD, Deputy Director, Office of Science \\ Michael F. Iademarco, MD, MPH, Director, Center for Surveillance, Epidemiology, and Laboratory Services}

MMWR Editorial and Production Staff (Weekly)
Charlotte K. Kent, $\mathrm{PhD}$, MPH, Editor in Chief Jacqueline Gindler, MD, Editor

Brian A. King, PhD, MPH, Guest Science Editor

Paul Z. Siegel, MD, MPH, Associate Editor

Mary Dott, MD, MPH, Online Editor

Terisa F. Rutledge, Managing Editor

Teresa M. Hood, MS, Acting Lead Technical Writer-Editor

Glenn Damon, Soumya Dunworth, PhD,

Catherine B. Lansdowne, MS, Donald G. Meadows, MA,

Srila Sen, MA, Stacy Simon, MA, Jeffrey D. Sokolow, MA, Technical Writer-Editors

Matthew L. Boulton, MD, MPH

Carolyn Brooks, ScD, MA

Jay C. Butler, MD

Virginia A. Caine, MD

Jonathan E. Fielding, MD, MPH, MBA

David W. Fleming, MD
Martha F. Boyd, Lead Visual Information Specialist

Alexander J. Gottardy, Maureen A. Leahy,

Julia C. Martinroe, Stephen R. Spriggs, Tong Yang, Visual Information Specialists

Quang M. Doan, MBA, Phyllis H. King,

Terraye M. Starr, Moua Yang,

Information Technology Specialists
Ian Branam, MA, Acting Lead

Health Communication Specialist Shelton Bartley, MPH,

Lowery Johnson, Amanda Ray,

Jacqueline N. Sanchez, MS,

Health Communication Specialists Will Yang, MA,

Visual Information Specialist 
Frequency of $C$. psittaci detection among all specimens and mean $\mathrm{Ct}$ value among $C$. psittaci-positive specimens were evaluated for each specimen type. Frequency of demographic and clinical characteristics were determined for probable and confirmed cases. All analyses were performed using SAS (version 9.4; SAS Institute). This activity was reviewed by $\mathrm{CDC}$ and was conducted consistent with applicable federal law and CDC policy.**

Among 82 ill workers identified by Virginia and Georgia departments of health, $33(40 \%)$ submitted a total of 54 specimens for real-time PCR testing. Thirteen of the 33 (39\%) workers tested had confirmed cases of psittacosis, and $20(61 \%)$ had probable cases of psittacosis (Table 1). Compared with probable cases, confirmed cases tended to be identified among older patients. A higher proportion of persons with confirmed cases were male, had a diagnosis of pneumonia, were hospitalized, or required intensive care unit admission. The most commonly submitted specimen type was nasopharyngeal swab (18 of 20 [90\%] of probable and eight of 13 confirmed cases). Nasopharyngeal swab specimens only were submitted by $13(65 \%)$ of 20 persons with probable cases and one of 13 persons with confirmed cases. Lower respiratory specimens were submitted by six (30\%) of 20 persons with probable cases and most (10 of 13) persons with confirmed cases. Timing of specimen collection relative to illness onset was similar for persons with probable (mean $=7$ days; range $=2-13$ days) and confirmed (mean $=6$ days; range $=1-14$ days) cases. Most patients received antibiotic treatment before or on the same day as specimen collection for C. psittaci testing (Table 1).

C. psittaci was most commonly detected in stool (four of five specimens) and lower respiratory specimens of bronchoalveolar lavage (two of two) and sputum (eight of 15), and less frequently in upper respiratory specimens of nasopharyngeal swabs (two [7\%] of 27) and oropharyngeal swabs (zero of one) (Table 2). Among C. psittaci-positive specimens, lower respiratory specimens had lower $\mathrm{Ct}$ values (mean $=29$; range $=26-31$ ), indicating higher bacterial load, than did nasopharyngeal swabs (Ct values 31 and 33) and stool specimens ( mean $=34$; range $=32-37$ ).

Among 13 patients with confirmed psittacosis, nine submitted multiple specimen types, allowing comparison of $C$. psittaci detection by specimen type (Table 3). Six patients had nasopharyngeal swab and sputum specimens tested; all sputa tested positive for $C$. psittaci, but only one nasopharyngeal swab tested positive. Three patients submitted stool and sputum specimens; all three sputum specimens tested positive for C. psittaci, and two stool specimens tested positive.

\footnotetext{
** 45 C.F.R. part 46, 21 C.F.R. part 56; 42 U.S.C. Sect. 241 (d); 5 U.S.C. Sect. 552a; 44 U.S.C. Sect. 3501 et seq.
}

TABLE 1. Characteristics of persons with probable and confirmed cases associated with a psittacosis outbreak - Georgia and Virginia, 2018

\begin{tabular}{|c|c|c|}
\hline \multirow[b]{2}{*}{ Characteristic } & \multicolumn{2}{|c|}{ Cases, no. (\%) } \\
\hline & $\begin{array}{l}\text { Probable* } \\
(n=20)\end{array}$ & $\begin{array}{c}\text { Confirmed }^{\dagger} \\
(n=13)\end{array}$ \\
\hline $\begin{array}{l}\text { Age, yrs, mean (range) } \\
\text { Male }\end{array}$ & $\begin{array}{r}36(22-55) \\
11(55)\end{array}$ & $\begin{array}{r}48(29-57) \\
10(77)\end{array}$ \\
\hline $\begin{array}{l}\text { Clinical characteristic } \\
\text { Physician-diagnosed pneumonia } \\
\text { Hospitalized } \\
\text { Admitted to intensive care unit }\end{array}$ & $\begin{array}{r}15(75) \\
12(60) \\
0(-)\end{array}$ & $\begin{array}{r}12(92) \\
11(85) \\
2(15)\end{array}$ \\
\hline \multicolumn{3}{|l|}{ Specimen type submitted ${ }^{\S}$} \\
\hline $\begin{array}{l}\text { Upper respiratory } \\
\text { Nasopharyngeal swab } \\
\text { Oropharyngeal swab }\end{array}$ & $\begin{array}{r}18(90) \\
1(5)\end{array}$ & $\begin{array}{l}8(62) \\
0(-)\end{array}$ \\
\hline $\begin{array}{l}\text { Lower respiratory } \\
\text { Sputum } \\
\text { Bronchoalveolar lavage }\end{array}$ & $\begin{array}{l}6(30) \\
0(-)\end{array}$ & $\begin{array}{l}8(62) \\
2(15)\end{array}$ \\
\hline $\begin{array}{l}\text { Nonrespiratory } \\
\text { Stool } \\
\text { Blood } \\
\text { Cerebrospinal fluid }\end{array}$ & $\begin{array}{r}0(-) \\
2(10) \\
1(5)\end{array}$ & $\begin{array}{l}5(38) \\
0(-) \\
0(-)\end{array}$ \\
\hline $\begin{array}{l}\text { Only nasopharyngeal specimens } \\
\text { submitted }\end{array}$ & $12(60)$ & $1(8)$ \\
\hline $\begin{array}{l}\text { Days from illness onset to specimen } \\
\text { collection, mean (range) }\end{array}$ & $7(2-13)$ & $6(1-14)$ \\
\hline \multicolumn{3}{|c|}{ Antibiotic treatment relative to specimen collection } \\
\hline Before & $9(45)$ & $10(77)$ \\
\hline Same day & $8(40)$ & $3(23)$ \\
\hline After & $3(15)$ & $0(-)$ \\
\hline
\end{tabular}

Abbreviation: $\mathrm{PCR}=$ polymerase chain reaction.

* Cases of illness in persons who worked at the Virginia plant during August 1-September 7,2018, or at the Georgia plant during August 13-September 28,2018 , and had physician-diagnosed pneumonia, fever, or chills with two or more of the following: headache, cough, or muscle aches. All probable cases in this analysis were real-time PCR-negative for Chlamydia psittaci.

t Cases of illness in persons who had real-time PCR detection of C. psittaci in at least one clinical specimen with or without meeting the probable case definition.

$\S$ A total of 18 patients submitted multiple specimens; therefore, the sum of patients submitting each specimen type exceeds 33 .

I The percentage of patients with doxycycline or a macrolide antibiotic treatment, first-and second-line antibiotics against psittacosis, initiated before, on the same day as, or after specimens for $C$. psittaci testing were collected. It could not be distinguished whether antibiotic treatment occurred before or after specimen collection for patients with antibiotic treatment initiation and specimen collection occurring on the same day.

C. psittaci was also detected in stool specimens of two patients with $C$. psittaci-negative nasopharyngeal swabs, including patient $A$, who had positive sputum and stool specimens but a negative nasopharyngeal swab. Ct values were lower in sputum than in stool specimens or nasopharyngeal swabs from the same patient (patients A, F, and G).

\section{Discussion}

This was the largest U.S. psittacosis outbreak in 30 years, the first U.S. outbreak in which human specimens were tested exclusively by real-time PCR, and the first that included testing of stool specimens. In this outbreak investigation, as in other 
TABLE 2. Real-time PCR test results, by specimen type, for all specimens tested in association with a psittacosis outbreak Georgia and Virginia, 2018

\begin{tabular}{|c|c|c|c|}
\hline Specimen type & $\begin{array}{l}\text { No. of } \\
\text { specimens } \\
\text { tested }\end{array}$ & $\begin{array}{l}\text { C. psittaci- } \\
\text { positive } \\
\text { specimens, } \\
\text { no. }(\%)\end{array}$ & $\begin{array}{c}\text { Ct value among } \\
\text { C. psittaci-positive } \\
\text { specimens, mean } \\
\text { (range) }\end{array}$ \\
\hline Upper respiratory & & & $32(31-33)^{*}$ \\
\hline $\begin{array}{l}\text { Nasopharyngeal } \\
\text { swab }\end{array}$ & 27 & $2(7)$ & \\
\hline Oropharyngeal swab & 1 & $0(-)$ & \\
\hline Lower respiratory & & & $29(26-31)$ \\
\hline Sputum & 15 & $8(53)$ & \\
\hline $\begin{array}{l}\text { Bronchoalveolar } \\
\text { lavage }\end{array}$ & 2 & $2(100)$ & \\
\hline Nonrespiratory & & & $34(32-37)^{\dagger}$ \\
\hline Stool & 5 & $4(80)$ & \\
\hline Blood & 3 & $0(-)$ & \\
\hline Cerebrospinal fluid & 1 & $0(-)$ & \\
\hline
\end{tabular}

Abbreviations: C. psittaci $=$ Chlamydia psittaci; $\mathrm{Ct}=$ cycle threshold; $\mathrm{PCR}=$ polymerase chain reaction.

* Data are from two nasopharyngeal swabs with Ct values 31 and 33.

† Data are only from stool specimens because there were no C. psittaci-positive blood or cerebrospinal fluid specimens.

published studies with real-time PCR-based detection of C. psittaci (3), C. psittaci was more frequently detected in lower respiratory specimens than in upper respiratory specimens, as reflected by detection in sputum but not nasopharyngeal swabs in five confirmed cases. Ct values in C. psittaci-positive specimens also suggest that bacterial load is higher in lower respiratory specimens than in nasopharyngeal swab specimens.
This analysis suggests that lower respiratory specimens are more useful than upper respiratory specimens for $C$. psittaci detection by real-time PCR. Although submission of lower respiratory specimens is encouraged, upper respiratory specimens are easier to collect, which could explain why nasopharyngeal swab was the most frequently submitted specimen type. Given that 60\% of patients with probable cases submitted only nasopharyngeal swab specimens, $C$. psittaci might have been underdetected in this outbreak; it is possible that more confirmed cases would have been detected if lower respiratory specimens were collected for testing in these patients.

Although only five stool specimens were tested in this outbreak, the frequency of $C$. psittaci detection in stool specimens was high, and in two patients $C$. psittaci was detected in stool and sputum specimens. Gastrointestinal symptoms have been reported among psittacosis patients $(6-8)$, and three of four patients with $C$. psittaci detection in stool specimens in this investigation also had gastrointestinal symptoms. However, whether these symptoms correspond with detection of $C$. psittaci in stool specimens has not been documented. Additional studies are needed to validate whether detection of C. psittaci DNA in stool specimens alone indicates presence of infectious bacteria in humans. Nonetheless, this investigation provides promising evidence that stool specimens might have utility for diagnosis of psittacosis using real-time PCR.

The findings in this report are subject to at least two limitations. First, specimens were not systematically collected and

TABLE 3. Clinical findings, hospitalization status, and real-time PCR test results in patients* with confirmed psittacosis cases ( $\mathrm{n}=13$ ) associated with a psittacosis outbreak - Georgia and Virginia, 2018

\begin{tabular}{|c|c|c|c|c|c|c|c|}
\hline \multirow[b]{2}{*}{ Patient } & \multicolumn{3}{|c|}{ Clinical findings and hospitalization status } & \multicolumn{4}{|c|}{ Real-time PCR result by specimen type (Ct value) ${ }^{\dagger}$} \\
\hline & Pneumonia $\$$ & Hospitalized & Admitted to ICU & Sputum & BAL & NP swab & Stool \\
\hline A & Yes & Yes & No & Pos (30) & -9 & Neg & Pos (37) \\
\hline B & Yes & Yes & No & Pos (30) & - & $\mathrm{Neg}$ & - \\
\hline C & Yes & No & No & Pos (28) & - & $\mathrm{Neg}$ & - \\
\hline$D^{* *}$ & Yes & Yes & No & Pos (26) & - & Neg & - \\
\hline E & Yes & Yes & No & Pos (26) & - & Neg & - \\
\hline $\mathrm{F}^{\dagger \dagger}$ & Yes & Yes & Yes & Pos (27) & - & Pos (33) & - \\
\hline G & Yes & Yes & No & Pos (28) & - & - & Pos (32) \\
\hline $\mathrm{H}$ & Yes & Yes & No & Pos (30) & - & - & Neg \\
\hline I & Yes & Yes & No & - & Pos (31) & - & - \\
\hline J & Yes & Yes & Yes & - & Pos (30) & - & - \\
\hline $\mathrm{K}^{\S \S}$ & No & Yes & No & - & - & Pos/Neg (31) & - \\
\hline $\mathrm{L}$ & Yes & Yes & No & - & - & $\mathrm{Neg}$ & Pos (38) \\
\hline$M$ & Yes & No & No & - & - & - & Pos (32) \\
\hline
\end{tabular}

Abbreviations: $\mathrm{BAL}=$ bronchoalveolar lavage; $\mathrm{Ct}=$ cycle threshold; $\mathrm{ICU}=$ intensive care unit; $\mathrm{Neg}=$ negative; $\mathrm{NP}=$ nasopharyngeal; $\mathrm{PCR}=$ polymerase chain reaction; Pos = positive.

* All specimens associated with an individual patient were collected on the same day unless otherwise noted. For example, sputum, NP swab, and stool specimens for patient $A$ were all collected on the same day, but specimens from patient A were not necessarily collected on the same day as were those from patient $B$.

† "Pos" indicates Chlamydia psittaci was detected. "Neg" indicates C. psittaci was not detected. Ct values represent the real-time PCR amplification cycle at which CPSIT_RS01985 amplification was first detected. Ct values are displayed only for C. psittaci-positive specimens, because CPSIT_RS01985 was not detected in C. psittaci-negative specimens.

$\S$ Radiograph confirmed pneumonia.

I Dashes indicate specimen type was not submitted to CDC.

** Sputum was collected 3 days after the NP swab.

t+ Sputum was collected 1 day after the NP swab.

$\S \S$ Two NP swabs were tested; one tested positive and one tested negative. The negative NP swab was collected 2 days after the positive NP swab. 


\section{Summary}

What is already known about this topic?

Real-time polymerase chain reaction (PCR) testing for Chlamydia psittaci, the bacterium that causes psittacosis, is faster and more specific than widely available serologic tests. However, the utility of diverse specimen types for C. psittaci detection by real-time $P C R$ is unknown.

What is added by this report?

During a large psittacosis outbreak in 2018, C. psittaci was most frequently detected in lower respiratory and stool specimens using real-time PCR.

What are the implications for public health practice?

It is important for clinicians and public health professionals to prioritize collection of lower respiratory specimens for C. psittaci real-time PCR testing. Findings of this outbreak investigation provide preliminary evidence that stool specimens might have utility for diagnosis of psittacosis.

were available from only a subset of patients. Because of this, the sample size overall and per specimen type was small. The small sample size limited ability to assess how severity of illness and antibiotic treatment affect $C$. psittaci detection for each specimen type. Second, although lower respiratory specimen collection was encouraged, psittacosis is characterized by dry cough, and lower respiratory specimens are difficult to obtain from mildly ill patients unless sputum collection is induced. Patients with severe illness, who likely also have higher bacterial load, might have been more likely to submit lower respiratory specimens.

Many factors influence $C$. psittaci detection in human clinical specimens; these include specimen type, timing of collection relative to illness onset and treatment with tetracycline or macrolide antibiotics, and severity of illness. Collecting information about these factors and systematic, serial testing of multiple specimen types from suspected cases might help inform optimal conditions for $C$. psittaci detection using real-time PCR. Public health professionals and health care providers should be aware that $C$. psittaci might not be detected if nasopharyngeal swab specimens alone are tested and that collection of respiratory specimens from multiple sites can improve detection by real-time PCR. Although lower respiratory specimens collected shortly after symptom onset might have the highest yield to diagnose psittacosis using real-time PCR, stool specimens might also have utility for diagnosis of psittacosis.

\section{Acknowledgments}

State and local partners; Deanna Crosby, Karen Daily, Melissa Ethridge, Rachel Franklin, Audrey Kunkes, Georgia Department of Public Health; Stephanie Kellner, Laura Kornegay, Patricia Bair, Meredith Davis, Julia Murphy, Laurie Forlano, Virginia Department of Health.

Corresponding author: Olivia L. McGovern, okp3@cdc.gov, 404-718-7202.

${ }^{1}$ Epidemic Intelligence Service, CDC; ${ }^{2}$ Division of Bacterial Diseases, National Center for Immunization and Respiratory Diseases, CDC; ${ }^{3}$ Virginia Department of Health; ${ }^{4}$ Georgia Department of Public Health.

All authors have completed and submitted the International Committee of Medical Journal Editors form for disclosure of potential conflicts of interest. No potential conflicts of interest were disclosed.

\section{References}

1. Balsamo G, Maxted AM, Midla JW, et al. Compendium of measures to control Chlamydia psittaci infection among humans (psittacosis) and pet birds (avian chlamydiosis), 2017. J Avian Med Surg 2017;31:262-82. PMID:28891690 https://doi.org/10.1647/217-265

2. Shaw KA, Szablewski CM, Kellner S, et al. Psittacosis outbreak among workers at chicken slaughter plants, Virginia and Georgia, USA, 2018. Emerg Infect Dis 2019;25:2143-5. PMID:31625859 https://doi. org/10.3201/eid2511.190703

3. Nieuwenhuizen AA, Dijkstra F, Notermans DW, van der Hoek W. Laboratory methods for case finding in human psittacosis outbreaks: a systematic review. BMC Infect Dis 2018;18:442. PMID:30165831 https://doi.org/10.1186/s12879-018-3317-0

4. Wolff BJ, Morrison SS, Winchell JM. Development of a multiplex TaqMan real-time PCR assay for the detection of Chlamydia psittaci and Chlamydia pneumoniae in human clinical specimens. Diagn Microbiol Infect Dis 2018;90:167-70. PMID:29291900 https://doi.org/10.1016/j. diagmicrobio.2017.11.014

5. Diaz MH, Waller JL, Theodore MJ, et al. Development and implementation of multiplex TaqMan array cards for specimen testing at Child Health and Mortality Prevention Surveillance site laboratories. Clin Infect Dis 2019;69(Suppl 4):S311-21. PMID:31598666 https://doi. org/10.1093/cid/ciz571

6. Anderson DC, Stoesz PA, Kaufmann AF. Psittacosis outbreak in employees of a turkey-processing plant. Am J Epidemiol 1978;107:140-8. PMID:623096 https://doi.org/10.1093/oxfordjournals.aje.a112516

7. Verminnen K, Duquenne B, De Keukeleire D, et al. Evaluation of a Chlamydophila psittaci infection diagnostic platform for zoonotic risk assessment. J Clin Microbiol 2008;46:281-5. PMID:18003799 https:// doi.org/10.1128/JCM.01153-07

8. Williams CJ, Sillis M, Fearne V, et al. Risk exposures for human ornithosis in a poultry processing plant modified by use of personal protective equipment: an analytical outbreak study. Epidemiol Infect 2013;141:1965-74. PMID:23176790 https://doi.org/10.1017/ S0950268812002440 